\title{
LA MUJER Y EL VELO EN EL MEDITERRÁNEO MUSULMÁN
}

\author{
Juan Antonio Pacheco Paniagua \\ Universidad de Sevilla
}

\begin{abstract}
Each text implies a critical method appropriate to it. In considering the veil as a text, its approach may be done with critical methods that can be able to understand such a difficult subject. Too much of the criticism of Maghrebian literature to date has focused on the narrowly sociological or realistic aspects, forgetting the symbolic. In this paper has been preferred to present an discursive approach having in maind the most of the actual views about the veil and its role in the Arab life.
\end{abstract}

De forma periódica y casi cíclica, el velo de la mujer árabe y musulmana es portada de artículos o reflexiones escritas en Occidente. Posiblemente, los dolorosos acontecimientos terroristas de estos momentos, derivarán en reflexiones de muy variado carácter y, no es ocioso suponer, que el tema del velo en la mujer musulmana, sea tema de debate en un próximo futuro. El aspecto mediático del velo y su institución y consolidación en el imaginario occidental, con el aporte de datos y controversias que representa la inmigración árabe y musulmana en Europa, constituye una tarea cuyo entendimiento pleno exige toda una gama de accesos intelectuales que conllevan la intromisión en los terrenos de la literatura, la psicología, la historia y la sociología, por no hablar de los referidos a la religión, las costumbres y la política.

Mujer velada/mujer des-velada como presencia constante en la historia del Islam mediterráneo, dentro del orbe islámico más amplio que se interna en las arenas de Arabia, en las montañas de Irán y en las lejanías de un Oriente al que nos aproximamos por la vía del exotismo y de la utopía literaria. En el Mediterráneo español, una mujer velada cuyo rastro puede seguirse a través de la rica literatura andalusí, nos proporciona la base y el punto de partida para preguntarnos por el momento en que fue posible determinar un comienzo de la dicotomía velo/des-velo y, desde ahí, rastrear el curso de una secuencia cargada del erotismo inherente al misterio de lo que no se conoce o que, tal vez, se deja ver en parte y en parte se esconde.

El alfaquí y tradicionista Abu Muhammad Abd al-Mun `im Ibn al-Fars, juez de Granada (1129-1200), nos ha dejado unos versos que propician el punto de partida de ese juego entre lo oculto y lo manifiesto que implica el velo femenino en la sociedad de al-Andalus:

"Ella apareció con un rostro como la luna llena, bajo un velo que parecía el crepúsculo.

Pero el velo era tan sutil sobre su frente, que, de puro sutil, parecía no existir. 
Pensé que el velo era un agua diáfana tras de la cual aparecía la verdad pura para el que la contemplaba" 1 .

Sutileza, inexistencia, crepúsculo: tres referentes de una misma esencia que, a lo largo del tiempo, se transformaron en sus contrarios semánticos de manera absoluta y cuyos orígenes motivadores de tal cambio habría que buscar en la historia, tanto de casi todos los pueblos mediterráneos de la antigüedad, como en los planteamientos sociales de las tribus beduinas del desierto de Arabia.

Sería harto difícil determinar el momento de aparición del velo femenino que, como todo fenómeno social no afecta del mismo modo, ni en el mismo momento, a las diversas capas de la población en las que se manifiesta. Por ello, sería casi utópico determinar el momento exacto de su aparición y empleo en el mundo musulmán, bien que su paternidad se venga atribuyendo al segundo califa del Islam Omar Ibn al-Jattáb.

Sin embargo, los testimonios etnográficos e históricos nos informan de la extensión del fenómeno así como de su carácter primigenio, diciendo que sobrepasa con mucho a la comunidad musulmana para englobar, aún hasta ayer mismo, a todo el litoral cristiano mediterráneo. Desde esa perspectiva, cualquier incursión en el pasado histórico demuestra que el velo es infinitamente más antiguo que la revelación coránica.

Según Blackman, es posible que la inscripción de Ramsés III en Madinat Habu contenga una alusión al uso del velo ${ }^{2}$, así como es posible verlo en las campesinas en muchas de las regiones del Alto Egipto. En el ámbito de las costumbres judías, velarse era para la mujer, cubrirse la cabeza y la frente, sobre todo para las mujeres casadas que, de salir a la calle sin el velo, podía ser motivo de repudio.

En la religión cristiana de los primeros tiempos, San Pablo exige que la mujer lleve sobre su cabeza una protección, medida que ha sido interpretada relacionándola con el mito de la caída de los ángeles del Paraíso, atraídos por las mujeres antes del Diluvio: la mujer debía cubrirse la cabeza para no atraer a los ángeles que eran de sexo masculino.

En principio, este postulado exige la presencia de otro actor, el hombre, en la escena de la costumbre y de su posible transgresión. De los ángeles y de su sexo, podemos descender a los hombres que podrían, a su vez, ser atraídos por la mujer sin velo, con el consiguiente conflicto social que ello plantearía para el marido de la desvelada y para todos sus parienies masculinos. Con ello también, se manifiesta otro de los aspectos sociales del velo: la sujeción de la mujer al hombre que, en el mundo árabe beréber, es la base de la cohesión social y el freno a la disolución de los vínculos clánicos.

Esta práctica, la de la mujer que se tapa la cabeza y la frente, es anterior al Islam, como hemos visto $\mathrm{y}$, con todo, persiste todavía en los círculos tradicionales magrebíes, por ejemplo. En estos casos, la mujer nunca se quita el velo, ni siquiera en el interior de sus

\footnotetext{
'E. García Gómez, El Libro de las Banderas de los Campeones de Ibn al-Sa ìd al-Magribí, Barcelona, 1978, p. 203.

${ }^{2}$ W.S. Blackman, Les fellahs de la haute Egypte, París, 1967, p. 22.
} 
hogares y, con el tiempo, ha llegado a constituir una forma de vestirse que implica un arte y una determinada técnica con resultados pretendidamente estéticos.

E1 Islam inaugura lo que podríamos denominar otra clase de velo, un artificio que remite a simbolismos inesperados, a reminiscencias y arcanos insondables y a cuestionamientos y repulsas de orden social en la modernidad, como tendremos ocasión de leer en lo que sigue.

Posiblemente, entre las numerosas connotaciones del modelo social que instaura el Islam en el seno de un sistema tribal reconocido y poderoso, destaca en principalísimo lugar el nuevo sistema de regulaciones de la sociedad en un medio demográfico y económico sedentario. Lo cierto es que el Islam es, además de una religión revelada, un conjunto de normas que se inscriben preferentemente en un contexto urbano, altamente mercantilizado y sometido a las normas y prácticas económicas del intercambio de bienes y servicios que, en La Meca, encontraban un asiento idóneo. Por otra parte, esa circunstancia, podría revertir en conductas promiscuas en lo tocante a la relación entre los habitantes de distinto sexo. Para un honor puntilloso, cuyos orígenes hay que buscar en la estratificación clánica de la sociedad, esa promiscuidad podría ser insoportable, no solamente para los individuos afectados, sino para la sociedad en su conjunto:

"Habitar en la proximidad de gentes con las que no existe lazos consaguíneos, en toda suerte de lugares públicos, podría ser causa de humillación. Por esta razón, se instauran todos los sistemas posibles de control, de forma que dicho contacto, nacido de la cercanía física, se vea impedido por todos los medios, incluidos los relativos a la violencia. De ello se deduce que todo extranjero o foráneo, podía verse impedido al acceso a los ambientes frecuentados por las mujeres. El corolario lógico de tal estado de espíritu es la adopción del vecino como pariente"

En una primera etapa, la forma más simple y asequible para separar a la mujer del hombre no familiar, fue la instauración del muro que representaba una mera cortina tras la cual permanecían las mujeres de la casa cuando en la misma había hombres que no eran de la familia. Ese velo que, ya en vida del Profeta, se recomendaba para mantener ante él, el debido respeto y correspondiente consideración, pasa a ser también el símbolo de la salvaguarda del honor y del respeto que los ajenos al círculo familiar, deben a la mujer musulmana. A continuación, ese velo vino a ponerse sobre el cuerpo de la mujer: espacio público frente a espacio privado; espacio de la mujer, intocable, frente al espacio del varón. Todo ello, además, con una confirmación revelada por Dios, que limita, establece linderos y cuantifica detalles:

"Di a los creyentes que bajen la vista con recato y que sean castos. Es más correcto. Dios está bien informado de lo que hacen. Y di a las creyentes que bajen la vista con recato, que sean castas y no muestren más adorno que los que están a la vista, que cubran su escote con el velo y no exhiban sus adornos sino a sus esposos, a sus padres, a sus suegros, a sus propios hijos, a sus hijastros, a sus hermanos, a sus sobrinos carnales, a sus mujeres, a sus esclavas, a sus criados varones fríos, a los niños que no saben aún de las partes femeninas. Que no batan ellas

${ }^{3}$ G. Tillion, Les ennemis complémentaires, Ed. de Minuit, París, 1960, p. 117. 
con sus pies de modo que se descubran sus adornos ocultos. ¡Volvéos todos a Dios, creyentes! Quizás, así, prosperéis" ${ }^{4}$.

Desde este momento, el cuerpo de la mujer se constituye como lugar de respeto, como un espacio protegido al que solamente tienen acceso los que se mencionan en los versículos sagrados. A su vez, este espacio se instaura como el núcleo intocable del espacio familiar y de la casa. Dejará, en lo sucesivo, de mostrar su presencia, tan sólo adivinada por quienes, desde fuera pasan cerca de él. La mujer acaba siendo un ser anónimo y su misma ocultación resaltará su valor de sagrada: la madre, la esposa, las hermanas, son sagradas para todos pero en diferente matiz y gradación, a medida que el círculo familiar se amplia. Todas ellas forman parte del santuario familiar que no es digno de mostrarse a los foráneos y que, ante todo, les está totalmente prohibido. Consecuentemente, todos los hombres dignos de este nombre, deberá velar por el honor de este santuario, pues toda mujer, por el hecho de serlo, comporta un riesgo de profanación, de la misma forma que un lugar santo tiene celadores que impiden el acceso de los intrusos.

Sin embargo, dentro de ese círculo femenino, serán las mujeres más jóvenes quienes cargarán con el peso de la vigilancia varonil más acendrada. Su virginidad intacta, su pureza, su integridad física, son metáforas que remiten a la cerrazón del clan, a la pureza de su nobleza. La ruptura de su integridad física genital, sería como la apertura definitiva de la muralla que rodea a una fortaleza que ha sido asaltada por la fuerza, y con ello, ha sido expuesta a posteriores ataques y rendiciones sin honor.

En última instancia, la sacralizad que se atribuye a la mujer y que se consolida externamente por medio del velo, nos conduce a conceptos relativos a las dimensiones antropológicas de la paradoja: la mujer musulmana es y no es objeto sagrado. El concepto de una sacralizad difusa y anónima conlleva, en el plano de las relaciones que mantiene con el mundo, una cierta intimidad debida a su inmanencia y a su cohabitación con los hombres. De ello se deduce que esa característica, la de lo sagrado unido a la mujer, pueda ser objeto de manipulación y de explotación.

Cuando se trata de abarcar intelectualmente esta complejidad laberíntica, se desemboca a menudo en lo insoluble y, sobre todo, en la paradoja del tabú. Como sabemos, hay dos clases de tabú: el inherente a los seres y a los objetos sagrados en sí mismos considerados, y el esporádico, impuesto por las circunstancias que, en cualquier caso se apropia de los rasgos del primero. En ambos casos, la prohibición en diferente de la relativa a la que pertenece a lo sagrado propiamente dicho. En este caso, los objetos están sujetos a prohibiciones, no por lo que constituye su especificidad ontológica, sino por accidente o, como en el caso de las revelaciones divinas, por una circunstancia que sobreviene y se sobrepone a esa esencialidad radical. A este respecto, es necesario observar cómo la sacralizad de la mujer velada, encierra un tabú que remite directamente a la sacralizad y el tabú del monumento religioso islámico por excelencia: la Ka`ba.

Como sabemos, la Ka`ba es un edificio de forma semejante a un cubo geométrico irregular en una de cuyas aristas se halla incrustada la Piedra Negra a la que todos los

\footnotetext{
${ }^{4}$ El Corán, XXIV, 30-31. Trad. J. Cortés, Madrid, 1984.
} 
peregrinos se acercan y tocan para recibir la bendición. Por otra parte, dicha edificación, vacía por dentro y con una puerta que solamente pueden abrir los especialmente designados para ello, se cubre con un velo negro que cuelga desde el techo hasta la base. Lugar de manifestación de un poder oculto pero constatable para los creyentes, el espacio de la Ka`ba es el espacio sagrado por antonomasia en el Islam. En tanto que objeto sagrado, la Ka 'ba y su origen material se remonta a los tiempos de Abraham que fue quien, de acuerdo con la tradición musulmana, la construyó con ayuda de su hijo Ismael, a cuyos descendientes fue confiada la custodia de su integridad material.

Monumento religioso desde mucho antes del advenimiento del Islam, fue desde el mismo cuando tiene lugar un hecho lleno de simbolismo: para que el Profeta pudiera entrar en el espacio sagrado que rodeaba la Ka 'ba y a su espacio interior mismo, fue necesario desposeer de su llave a una mujer que era la encargada de custodiarla en tanto que guardian(a) del lugar santo. Este acontecimiento singular no se llevó a cabo con facilidad, pues hubo de contar con la resistencia de la mujer a entregar la llave, cosa que hizo tras ser amenazada de muerte por su propio hijo en caso de que se negara a hacerlo. Hay quien ha visto en este gesto, la manifestación del paso de la sociedad matriarcal a la patriarcal. En cualquier caso, en adelante serán varones los que tendrán la llave de la edificación y quienes mantendrán su integridad y solidez.

Durante el período pre-islámico, parece que los beduinos reservaron a la mujer una función especial en sus escasas manifestaciones religiosas públicas. Así, como hemos visto, la custodia de la llave de la Ka'ba. Nos consta también la presencia de pitonisas y adivinadoras en la sociedad de los tiempos anteriores al Islam, a las que los árabes del momento consultaban antes de acometer empresas de riesgo. Por otra parte, sabemos también que había tres diosas en el panteón religioso de la Arabia central y que las mismas eran consideradas por sus devotos como hijas de Dios que, con la llegada del Islam desaparecieron para siempre en la conciencia religiosa musulmana.

El Islam unificará la dispersión de esa conciencia religiosa beduina en el culto a un solo Dios, señor absoluto del Universo. Presente en todas las instancias de la vida del creyente, trasciende todo espacio sagrado, permanece por encima y lejos del mismo abarcándolos con su Poder absoluto. Con ello, los antiguos espacios sagrados limitan su poder y se aseguran su supervivencia en el seno de una creencia en un Ser superior que los engloba y protege.

De todo lo dicho, bien que esquemáticamente y a mero título de introducción temática, podemos deducir algunos de los rasgos que comporta el velo en la mujer musulmana. Rasgos éstos que, por otra parte, pueden ser comunes a otras culturas del orbe mediterráneo semítico y que, en conjunto, manifiestan las estructuras antropológicas de un imaginario fuertemente arraigado. En el caso del Islam, además, el velo femenino se instala en el seno de la paradoja y de la aparente contradicción, no solamente desde el punto de vista social actual, sino desde la perspectiva histórica más acreditada documentalmente. Este será el caso de la institución del velo en la mujer andalusí que, a juzgar por las referencias literarias, no era la reclusa que propicia su sacralizad anteriormente mencionada.

Se cuenta que el poeta al-Ramadí, paseándose un viernes por el jardín de los Banu Meruán de la Córdoba califal, entabló conversación con una joven y no deja de hablarle hasta conseguir de ella una cita para el viernes siguiente. Jalwa, que posiblemente era el 
nombre de la chica, llevaba seguramente un velo y es inconcebible, en los parámetros citados en páginas anteriores, que un hombre hubiera podido hablar tanto tiempo a una mujer en público sin provocar advertencias descorteses. La hipótesis, verosímil por otra parte, que podría justificar tal circunstancia es la de una cierta transgresión de la mujer respecto de su propio carácter sacro y de su función en la sociedad de al-Andalus.

Transgresión que llegaría al colmo de la osadía en el caso que nos refiere Ibn Hazm (m. 1063) en El collar de la paloma y de cuyos hechos fue testigo el polígrafo cordobés: Ibn Sahl al-Háyib, de Sicilia, acaba de pasar por una de las avenidas cordobesas. Una mujer, impresionada por su belleza, le sigue, y cuando él desaparece en el recodo de la calle, se arroja al suelo para besar las huellas de sus pies. El mismo Ibn Hazm, escribe unos versos que denotan una grado de intimidad con una mujer, a la que suponemos sin velo, inusitado en otros lugares de la geografía musulmana del momento.

"Me quedé con ella a solas, sin más tercero que el vino, mientras el ala de la tiniebla se abría suavemente.

Era una muchacha sin cuya vecindad perdería la vida. ¡Ay de t! ¿Es que es pecado este anhelo de vivir?

Yo, ella, la copa, el vino blanco y la oscuridad parecíamos tierra, lluvia, perla, oro y azabache" 5

Es posible suponer que entre la población artesana o campesina andalusí las mujeres no llevaban velo o, todo lo más, con la cabeza cubierta con un pañuelo que dejaba ver el rostro con claridad. De este modo, el acceso visual permitía el posterior acceso amoroso y su proposición por parte del hombre. Fue en las afueras de Sevilla, y propiciado por estas circunstancias, donde el rey sevillano al-Mu`tamiz se fijó en una lavandera que llegaría a ser su mujer legítima con el nombre de I’timad. El mismo monarca, paseándose con Ibn Ammar por el barrio de los yeseros y los caleros de Sevilla, se cruzó con una mujer de gran belleza, con la que entabló conversación en el tono más libre.

Sin embargo, el caso y ejemplo más claro de la libertad social de la mujer musulmana andalusí, con velo o sin él, es el de Walláda. Hija del califa al-Mustakfí, aprovechó la muerte de su padre para liberarse por completo del sistema patriarcal masculino. Abrió un salón que atraía a los más altos personajes y a los más famosos hombres de letras. Su aspecto desenfadado, su desdén por el velo, lo atrevido de su conversación y la excentricidad frecuente de su conducta, mostraban claramente que transgredía la norma.

Junto al grado de emancipación de la condición femenina que muestra Walláda, hay que traer a colación un complemento de dicha conducta transgresora en lo social y en lo religioso que también tuvo ocasión de hacerse manifiesta en al-Andalus y en algunos lugares de Oriente: la esclava con aspecto masculino que también es objeto de deseo.

De lo dicho no hay que deducir precipitadamente que todas las mujeres andalusíes gozaban de tamaña libertad de costumbres. La censura tradicional estaba al acecho y, en

\footnotetext{
${ }^{5}$ Citado por J. Vernet, Literatura árabe, Barcelona, 1970, p. 115.
} 
consonancia con la norma establecida por la religión, algunos poetas recriminan en sus versos la conducta ligera de mujeres y hombres. Así es el caso de Ibn Musadif de Ronda:

"Impide a tus mujeres legítimas salir y, cuando lo hagan, no muestres un rostro sereno.

No prestes atención a la que, de entre ellas, se encolerice: esta cólera es una prueba de que conseguirás tus fines.

¡Eh!, ¿no son como las perlas por la apariencia? Las perlas salen del nácar para ser puestas en un estuche" 6 .

Ese estuche, que en principio se manifestaba por el recinto del hogar familiar, amplia su resonancia metafórica en el constituido por el velo en sus diferentes variedades y texturas. Para el poeta andalusí, un cuerpo púdicamente velado parecía procurar mayor alicientes a la imaginación y al deseo. El traje ligero de la mujer, que deja adivinar sus formas armoniosas, es fuente de inmediata inspiración para algunos de ellos, como Ibn Xuayb:

"Quítate el waxy (tela de seda estriada en oro), pues esconde una belleza que los más ricos vestidos no han poseído jamás" 7 .

De la misma forma que los poetas andalusíes son los cronistas idóneos para ofrecernos el panorama de la vida amorosa, e incluso cotidiana, de la mujer musulmana del momento, la literatura de los países árabes mediterráneos, en especial Argelia, viene a ser el documento más accesible para introducirnos en las circunstancias de la condición femenina musulmana y, en ella, la función del velo. Cuando esta literatura es el producto de una mujer escritora, el resultado adquiere los tintes de un documento social. En lo referido al Magreb en general y a Argelia en particular, la escritura femenina introduce en el dominio de lo público, elementos acerca de los cuales no existe la costumbre de ser expuestos al debate colectivo: psicología, lógica, gestualidad femenina, instauran en ese debate las dimensiones de un acontecimiento de amplias repercusiones sociales e incluso políticas. En el caso de Argelia, la mayor parte de las novelas escritas por mujeres que vivieron la revolución y la larga guerra de la independencia del país (1954-1962), integran esa circunstancia en el relato, insistiendo en la función de la mujer en el combate y, como resultado, su derecho a tomar la palabra y el gesto liberador.

Cherifa Benabdessadok analízale discurso de la mujer argelina contemporánera que se inscribe sus actos en la revolución nacionalista y distingue tres tipos de enunciados:

1. el discurso mítico que se remonta a la estética revolucionaria y en el que la presencia del velo queda subsumida por los hechos que aquella simboliza.

2. el discurso falseado que esquiva la opresión específica y multiforme de la mujer y cuya fórmula expresiva podría ser: la emancipación de la mujer pasa por la edificación nacional, sin especificar etapas ni medios para tal liberación.

\footnotetext{
${ }^{6}$ H. Pérès, Esplendor de Al-Andalus, Madrid, 1983, p. 400.

${ }^{7}$ Ibíd, p. 406.
} 
3. el discurso que enmascara un rechazo por la liberación y acepta las propuestas del pasado ${ }^{8}$.

Uno de los documentos literarios de más amplia repercusión en la crítica literaria argelina, es la novela de Assia Djebar, Femmes d'Alger dans leer appartement ${ }^{9}$ donde la autora evoca los combates que entablaron las mujeres junto con los hombres, contra un enemigo común, para resaltar que constituyeron raros y felices momentos en los que las barreras de género se vieron derribadas por un instante y en los que el velo, como muro de separación, dejó de existir. Sin velo, en medio del combate, la mujer musulmana argelina combatiente tenía, por fin, una rostro, una voz y un cuerpo:

"Au terme des combats héroïques, la femme regardait, la femme criait : regard témoin tout au long de la bataille que prolongeait le hululement por encourager le guerrier (cri allogé trouant l'horizon comme un gargouillis infini du ventre, un appel sexuel, un envol total" 10 .

En esta obra, como en otras de la misma temática, cuya relación detallada no es objeto del presente trabajo, la crudeza expresiva no intenta presentar reivindicación feminista alguna separada de la lucha que llevan a cabo los hombres. Sin embargo, dejan entrever la reclamación del derecho de entrar en la vida pública y social y denuncian una separación que, fundada en la distinción de los géneros y en las señas externas de la misma, confunde en una misma negación el ser social y la feminidad.

La división tradicional entre espacio doméstico y espacio público, escribirá Fátima Mernissi, es una expresión de poder y de jerarquía. Esta división reposa sobre la distinción más profunda entre lo sagrado y lo profano, entre lo velado y lo descubierto, considerando a los ámbitos conceptuales como divididos por una fisura indestructible ${ }^{11}$.

La narración se hace eco de esta dicotomía e insiste en la obligación moral, para que la mujer sea sujeto de conocimiento y discurso, de que se la acepte a un mismo tiempo, como ciudadana y como ser físico.

Tal reivindicación no es exclusiva de la mujer escritora, sino que la comparten asimismo los autores de relatos contemporáneos argelinos. Este será el caso de Kateb Yacine y su novela Nedjma, publicada en 1956, en plena guerra argelina y cuyo argumento resume J. Dejeux:

"L'imagination créatrice aidant, Nedjma s'est sublimée femme-Algérie vierge ou mèreAlgérie. Le débat entre l'amour pour la cousine et l'amour pour la Révolution (découverte faite en prison auprès des militants) entraine une amplification au second degré de cette Nedjma. Le poète récuperait aussi son amour frustré sous le symbole de la Révolution. L'Algérie en tant que femme, toujours vierge après chaque viol, mère ou déesse nationale, Kahéna ou amazone casquée et guerrière, occupa donc dans l'esprit de l'auteur la place de la

\footnotetext{
${ }^{8}$ The Maghreb Review, 1984, vol 9, p. 87.

${ }^{9}$ París, 1980.

${ }^{10}$ Ibíd, p. 188.

"F. Mernissi, Sexe, Idéologie, Islam, París, 1983, p. 155.
} 
cousine-soeur. Les jeunes cousins âgés, dans le roman, de seize à dix-huit ans, tournent autour de Nedjma, jaloux les uns des autres. L'image de l'Algérie, investie par l'Autre, prendra, au fur et à mesure de leur conscienciation politique, plus de consistance que la femme réelle" 12 .

De una forma consciente o inconsciente, ambos términos aplicables a la paradoja que conlleva la operación de velar/des-velar, la peripecia de Nedjma se transmuta en la de toda una nación que, para recuperar su independencia debe ser, primero, liberada de la tutela colonial y, después, recuperar su identidad. En la dinámica actancial de la obra aparecen así elementos que catalizan el proceso de autorecuperación: la sangre derramada de la virgen, la descomposición de los lazos de la tribu, la ausencia de los padres. Nedjma, la estrella vagabunda acaba siendo recuperada por su tribu, para gozar de nuevo de una función central, una vez purificada. Permanecerá en el campamento de las mujeres, aunque nadie podrá acercarse a ella, verla o dirigirle la palabra. Cuando los ancestros necesiten una virgen para incendiar la ciudad, la elección recaerá sobre ella, aunque, en esta ocasión, se tratará de una virgen purificada y vuelta a sus origenes.

En este caso, nos enfrentamos al ritual del desvelamiento, tan sagrado como el de la imposición del velo, el mismo al que recurrían los beduínos del desierto arábigo cuando la vida de la tribu se veía amenazada, ritual que, por otra parte, es recurrente en el transcurso de los hechos que tienen lugar en la guerra de liberación argelina.

En este caso, sin embargo, no se tratará de una tribu que se enfrenta a un peligro desconocido, sino toda una nación que se levanta para hacer frente a una ocupación extranjera que está en su tierra desde el año 1830. En un determinado momento de este combate, la mujer y el velo tendrán un puesto central en la dinámica de los acontecimientos.

Uno de os observadores privilegiados de este proceso, es Frantz Fanon según el cual, se puede olvidar durante un tiempo que un musulmán no come cerdo o se abstiene de relaciones sexuales durante el mes de Ramadán, sin embargo el velo de la mujer aparece y se hace sentir con tal rotundidad, que bastaría él solo para caracterizar a la sociedad árabe en su totalidad. Con el velo, las cosas se precisan en sus rasgos definitorios y se ordenan mejor en el espacio y en el tiempo y la mujer argelina es, ante todo, ese objeto que disimula su presencia tras el velo. Tal vez precisamente por este hecho, o en virtud del mismo, ella delimitará dos mundos, el del colonizador y el del colonizado. Su sola presencia constituye una frontera, un límite que se opone a la voluntad expansionista del ocupante. La mujer mediterránea argelina, y su velo que parece formar parte indivisa de su personalidad, exacerbarán los ánimos ${ }^{13}$.

La presencia activa de la mujer argelina y el velo en el seno de la controversia nacionalista previa, simultánea y subsiguiente a la independencia, en 1964, han llevado a la formulación de variadas hipótesis y marcos interpretativos particulares y heterogéneos. Los antropólogos y los sociólogos, en particular, han tratado de descubrir bajo esa presencia

\footnotetext{
12 J. Dejeux, "Les structures de l'imaginaire dans l'oeuvre de Kateb Yacine ", en Mélanges, Le Tourneau, Aix-enProvence, 1973, p. 268.

${ }^{13}$ F. Fannon, Sociologie d'une révolution, Paris, 1959.
} 
sutil del velo un poder oculto hasta el momento, de tal manera inocuo que parecía haber pasado desapercibido a todas las miradas. Bajo las apariencias patriarcales, dirán tales estudiosos, la sociedad árabe argelina de descubre como profundamente matriarcal. Tras el patriarcado visible y manifiesto, se constataría la existencia de un matriarcado de base. La función de la madre argelina, la de la abuela, la tía, se hace objeto de inventarios, clasificaciones y adscripciones de todo tipo, de forma que la potencia colonial llegará a descubrir que ese matriarcado que, de momento, se esconde tras un velo, es el verdadero y auténtico núcleo de la resistencia: "Il faut que nous allions les chercher derrière le voile aù elles se dissimulent, et dans les maisons où l'homme les cache".

De este modo, se hará necesaria la definición y el diseño de una nueva estrategia, una guerra más sutil con los rasgos decisivos de una auténtica guerra psicológica. Por otra parte, dicha estrategia conllevará la reaparición, si es que era necesaria en los tiempos de la guerra argelina, del espíritu misionero cristiano y la investidura de una fe patriótica inesperada en los espíritus de los colonizadores.

Desde el punto de vista de las mujeres argelinas, con velo o sin él, asistiremos a un movimiento de solidaridad comunitaria, circunstancia que, a su vez, incidirá en la conducta de los hombres. En todos los casos, la controversia muestra sus rasgos más claros: a la ofensiva colonialista en torno al velo, el colonizado (la colonizada) opondrá el culto al velo. Éste, que hasta entonces había sido la expresión de una voluntad de anonimato, de reclusión y de silencio, se convierte en portador de un mensaje, a la vez que se constituye en símbolo de la resistencia. De esta forma, lo que en su momento estuvo ligado al tabú y a la sacralizad, ahora lo estará a la propaganda a todos accesible y a la profanación en su sentido más etimológico posible, teniendo en cuenta que el velo servirá, en la lucha, para camuflar bajo él armas y municiones.

Cuando la lucha por la independencia exige una mayor presencia de la mujer en su estrategia, el velo será un estorbo y el cuerpo femenino adquiere los caracteres de un varón combatiente en sus rasgos externos. La ciudad conquistada, reconquistada, es así la forma metafórica de la autoconquista del cuerpo femenino: el velo de la colonia, se sustituye por lo diáfano de la independencia. Libertad por libertad, cuerpo por cuerpo. El intercambio está servido y consumado.

No podemos olvidar que en todo momento, hemos venido hablando de la mujer velada o des-velada musulmana urbana. Sería necesario, para completar el panorama discursivo, la descripción de los caracteres de la adopción del velo por parte de la mujer rural, argelina, tunecina o libia, por poner los tres ejemplos más "mediterráneos" posibles. Por otra parte, tampoco debería descuidarse el tratamiento teórico que el tema del velo ha tenido en los intelectuales preocupados por la modernización y puesta al día de la vida de la mujer en el mundo árabe y el impedimento que, para dicho proceso, constituye el velo.

A este respecto, es preciso aludir a los esfuerzos renovadores de los intelectuales egipcios de comienzos del siglo XX y finales del XIX, que insistieron denodadamente en la necesidad de alejar a la mujer egipcia, y mediterránea también, de la presencia atenazante del velo. En este caso, hay que contar con la aportación decisiva de Qásim Amín (m. 1908) y de su obra La Nueva Mujer, donde el autor es meridianamente claro cuando se refiere a las trabas que representa el velo para el desarrollo intelectual de la mujer árabe: 
"Tal vez no haya otro pecado en el velo que el ser nefasto para la libertad humana y el llevar a la mujer allí donde no pueda gozar derechos que la Ley divina le concede, así como también las leyes positivas, convirtiéndola prácticamente en una menor de edad que no puede ocuparse de nada de aquello que le atañe. Aunque la ley reconoce el derecho de administrar su vida en un plano de igualdad con los varones, y aunque en este sentido sea considerada libre como ellos, la coloca en una cárcel. Mas si este fuera el único pecado del velo, con sólo eso bastaría para odiarlo y alejarlo de toda disposición que enaltezca el amor y el respeto de los derechos a gozar de las libertades. Sin embargo, todavía hay males que el velo encierra y que están por encima de todos los que anteceden, siendo el principal de ellos, el que el velo se interpone entre la mujer y su educación" ${ }^{14}$.

Qásim Amín, deudor de la ciencia positivista francesa que inaugurara Comte, se muestra en su propuesta como entusiasta decidido en pro de la occidentalización de la mujer egipcia y, con ello, de la desaparición del velo, como única forma de llevar a cabo la reforma de la sociedad. Así, estableciendo un paralelismo entre enfermedad social y enfermedad corporal, se pregunta si es posible recetar un medicamento antes de conocer la patología del paciente y los síntomas concomitantes. De la misma forma, sigue diciendo, si la enfermedad se encuentra en una nación, lo correcto será establecer previamente su sintomatología y la anamnesia que nos permita prescribir el medicamento adecuado. Y no otra cosa será la idea que preside la redacción de gran parte de su obra, sobre todo en su capítulo dedicado al velo.

\footnotetext{
${ }^{14}$ Q. Amín, La Nueva Mujer, Instituto Egipcio de Estudios Islámicos, Madrid, 2000, p. 121. (trad. e introducción de J. Antonio Pacheco)
} 
